Reprinted from Journal of Phystcal Oceanography, Vol. 11, No. 6, June 1981 American Meteorological Society Printed in U. S. A

Satellite Determination of the Mesoscale Variability of the Sea Surface Temperature P. Y. Deschamps and R. Frouin

L. WALD 


\title{
Satellite Determination of the Mesoscale Variability of the Sea Surface Temperature
}

\author{
P. Y. Deschamps and R. Frouin \\ Laboratoire d'Optique Atmosphérique, Equipe associée au C.N.R.S., Université des Sciences et Techniques de Lille, France
}

\author{
L. WALD
}

Centre de Télédétection et d'Analyse des Milieux Naturels, Ecole Nationale Supérieure des Mines de Paris, 06560 Valbonne, France (Manuscript received 5 September 1980, in final form 11 February 1981)

\section{ABSTRACT}

Satellite infrared data have been used to investigate the mesoscale variability of the SST (sea surface temperature) field. A statistical analysis of the SST field has been performed by means of the structure function. Results give the equivalent power-law exponent $n$ of the spatial variance density spectrum $E(k) \sim k^{-n}$. The exponent $n$ was found to vary from 1.5 to 2.3 with a mean value of 1.8 in the range of scales $3-100 \mathrm{~km}$ which is in agreement with previous one-dimensional analysis from shipborne and airborne measurements. These observed values of $n$ are discussed and compared with the values predicted by turbulence theories.

\section{Introduction}

Present-day satellite infrared radiometers permit the determination of the mesoscale SST (sea surface temperature) field on an operational basis thanks to their improved radiometric performances, which typically are of a few tenths of ${ }^{\circ} \mathrm{C}$ for a nadir resolution of $1 \mathrm{~km}^{2}$. This gives a potential tool for a systematic investigation of mesoscale thermal features such as thermal fronts, eddies and plumes which have been already observed and studied by means of IR pictures or derived SST maps. In addition to these observable features, a part of the SST field must be considered as random and containing some other information which can only be retrieved by a statistical analysis - e.g., the spectral density of variance.

Attempts to compute the spatial spectrum of the SST have previously been made by McLeish (1970), Saunders (1972a) and Holladay and O'Brien (1975), from airborne infrared measurements along an aircraft track. Examples of mesoscale spectra have also been determined from shipborne measurements (Voorhis and Perkins, 1966; Fieux et al., 1978). Satellite observations give a unique opportunity to investigate the mesoscale variability of the SST field, down to scales of $1 \mathrm{~km}$, at any given time, with a frequency which is limited only by the cloud cover. In the present study, we intend to demonstrate the feasability of using satellite data to obtain statistical parameters of the mesoscale SST field.

\section{Statistical analysis of the SST field}

Studies of the variability of the temperature (or any scalar) field usually make extensive use of spec- tral methods, i.e., the computation of the density spectrum of the scalar variance by means of Fourier transformation or autocorrelation function, to obtain a typical power law which characterizes the variability of the temperature field and which can be related to turbulence theories. In the present study, the structure function has been employed in order to more accurately determine the power-law exponent in the presence of the large noise level found in satellite infrared data.

\section{a. Structure function}

If the SST field is considered as being an isotropic random process with homogeneous increments (at least locally), the structure function can be computed as

$$
D_{T T}(h)=1 / 2 \overline{[T(x+h)-T(x)]^{2}},
$$

where $T(x)$ is the temperature at $x, h$ the spatial scale, and an overbar denotes an average operator. In the following, $k$ denotes the wavenumber of the form $k=h^{-1}$.

The main advantage of the structure function $D(h)$ when compared with the spectrum of the variance density $E(k)$ or with the autocorrelation function $B(h)$ is that its experimental determination is more accurate and much less affected by random variations because only increments are taken into account (Panchev, 1971). An example is given in Fig. 1 where both $E_{T}(k)$ and $D_{T T}(h)$ have been computed and are shown for the same sample of the SST field, measured by the AVHRR (Advanced Very High-Resolution Radiometer) experiment on board the TIROS-N 

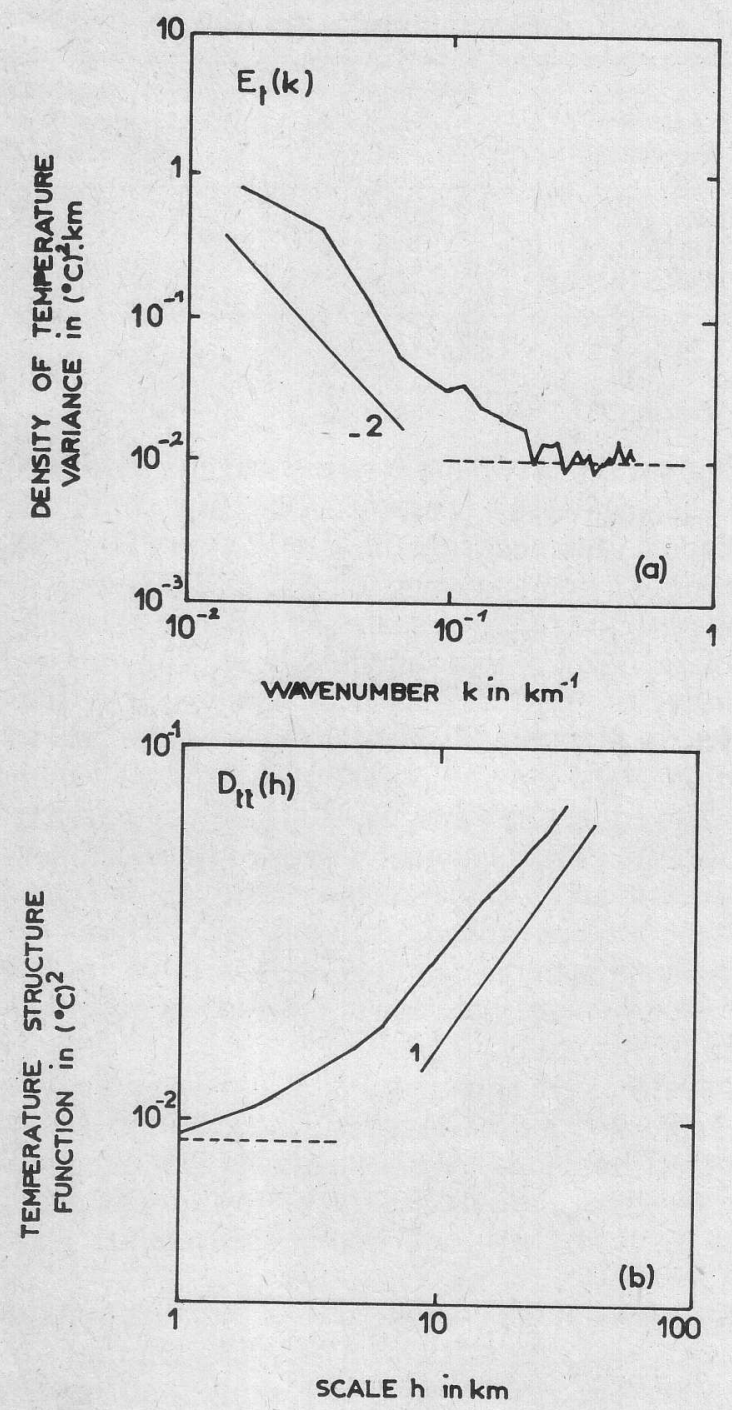

FIG. 1. Comparison between the (a) density of temperature variance $E_{T}(k)$ and (b) the structure function $D_{T T}(h)$, computed from AVHRR data, 17 July 1979, over the Bay of Biscay $\left(45^{\circ} 30^{\prime} \mathrm{N}, 4^{\circ} 30^{\prime} \mathrm{W}\right)$. The dashed line indicates the radiometer noise level.

satellite. This example shows clearly that the structure function is more regular than the spectrum, allowing an easier determination of the characteristic parameters, e.g., the power-law exponent given by the slope when using logarithmic coordinates.

\section{b. Interpretation of the structure function}

The structure function $D(h)$ represents the statistical influence of a point upon other points at distance $h$. For a homogeneous and isotropic random process, $D(h)$ and $B(h)$ are linked by

$$
D(h)=[B(0)-B(h)] \text {. }
$$

As $B(h)$ and $E(k)$ are the Fourier transformations of each other, $D(h)$ may thus be related to $E(k)$ (Panchev, 1971):

$$
D(h)=\int_{0}^{\infty}(1-\cos 2 \pi k h) E(k) d k
$$

for a one-dimensional analysis.

In the inertial range, the spectrum is usually characterized by

$$
E(k) \sim k^{-n}
$$

From (3), it can be shown that the structure function may then be written as

where

$$
D(h) \sim h^{-p},
$$

$$
n=p+1
$$

when $n>1$ in order to respect the convergence of the integral (3) at small scales. The exponent $n$ of the spectral density thus can be alternately determined from the structure function using (6), if the field under study is homogeneous.

Two kinds of error may affect the satellite-based determination of the SST field-instrumental data noise and atmospheric effects.

Although the structure function has the advantage of being much more regular than the spectrum, the study of the structure function and of its shape is generally limited by the noise level at the smallest scales. This effect is illustrated in Fig. 1b, where the observed slope giving the power law exponent of the structure function decreases from $\sim 1$ at large scales to zero at the smallest scales.

In the particular case of random fluctuations due to an instrumental white noise, both the spectral density and the structure function reduce to constants $E_{n}$ and $D_{n}$, with $E_{n}=\sigma_{n} / k_{0}, D_{n}=\sigma_{n}$, where $\sigma_{n}$ is the noise variance and $k_{0}$ the upper wavenumber limit of the spectral analysis. This noise constant adds to the actual structure function of the SST, which restricts the exponent determination at the largest scales where the noise constant may be neglected $\left[D_{n} \ll D(h)\right]$. When necessary, a suitable spatial smoothing may reduce the noise, with a corresponding degradation of the ground resolution.

Smoothing also introduces a bias in the determination of the structure function. If $D_{F}(h)$ is the structure function of the smoothed field, and $Q$ is the convolution square of the smoothing function $F$ it may be shown (Matheron, 1970), that

$$
D_{F}(h)=D * Q-A
$$

where $*$ is the convolution operator and $A$ is a constant, i.e.,

$$
A=\int_{-\infty}^{+\infty} D(u) Q(u) d u
$$


When $F$ is the spatial average in a square of side $a$, $A=D(a) / 3$ for $p=1$. As with the noise constant, the influence of the bias introduced by smoothing rapidly decreases when $h$ increases, and is less than $10 \%$ at $h>3 a$. Above this scale, the influence of smoothing can then be neglected $[A \ll D(h)]$.

The atmospheric transmittance $\tau$, in the $10.5-12.5$ $\mu \mathrm{m}$ channel generally used on satellites, mainly depends on the atmospheric water vapor content and typically varies between 0.9 and 0.3 (Kneizys et al., 1980). The radiometric temperature $T_{B}$ measured from space must thus be expressed as

$$
T_{B}=\tau T_{W}+(1-\tau) T_{a},
$$

where $T_{W}$ is the water temperature and $T_{a}$ an appropriate mean air temperature. From (9) it is obvious that the structure function computed from satellite data depends not only on the variations of $T_{W}$, but also of $T_{a}$ and $\tau$. Atmospheric variability generally is assumed to be at larger scales than oceanic variability, so that atmospheric fluctuations could be neglected at scales $<100 \mathrm{~km}$. Nevertheless, the satellite determination of the structure function may on some occasions be partially contaminated by air temperature and water vapor variations, but it is very unlikely that this would occur over the open sea where it can be assumed that atmospheric parameters are stable within the scale range. A further study involving satellite and surface measurements along the same track would have been necessary in order to resolve this problem. Assuming a constant atmosphere,

$$
\begin{aligned}
T_{B}(x+h)-T_{B}(x) & =\tau\left[T_{W}(x+h)-T_{W}(x)\right] \\
D_{T_{B} T_{B}(h)} & =\tau^{2} D_{T_{W} T_{W}}(h),
\end{aligned}
$$

where the influence of the atmosphere affects only the determination of the structure function amplitude, and not the determination of the power-law exponent $p$. Because the atmospheric transmittance cannot be accurately determined over the oceans, only one parameter of the structure function can be determined from a satellite; this is the power-law exponent $p$ obtained from the slope of the curve in a log-log plot.

The hypothesis of the homogeneity of the random field must be verified, otherwise erroneous determinations of the exponent could be obtained. For example, a frontal zone would have a spectrum $E_{T}(k)$ $\sim k^{-2}$, but $D_{T T}(h) \sim h^{2}$. Since these exponents are close to the physically expected values, it is necessary to carefully check the homogeneity of the SST field and to remove the existing trend if necessary. When the mean horizontal SST gradient $\partial T / \partial x$ is small, it is sufficient to take

$$
(\partial T / \partial x)^{2} h^{2} \ll D(h)
$$

over the study range of scales; otherwise, the standard procedures must be applied to detrend the data.
TABLE 1. Radiometer performances of the satellite experiments used in this study.

\begin{tabular}{lcc}
\hline \hline $\begin{array}{c}\text { Satellite } \\
\text { experiment }\end{array}$ & $\begin{array}{c}\text { Ground resolution } \\
\text { at nadir } \\
\left(\mathrm{km}^{2}\right)\end{array}$ & $\begin{array}{c}\text { Noise equivalent } \\
\text { temperature } \\
\text { difference }\left({ }^{\circ} \mathrm{C}\right)\end{array}$ \\
\hline VHRR/NOAA-5 & 1 & 0.8 \\
HCMR/HCMM & 0.25 & 0.3 \\
AVHRR/TIROS-N & 1 & 0.1 \\
\hline
\end{tabular}

\section{Results}

The results of two independent but complementary studies are hereby presented. The first study deals with data obtained from the VHRR (Very High-Resolution Radiometer) on board NOAA-5, and was limited to the range of scales $40-100 \mathrm{~km}$ because of the large level of instrumental noise. The improved radiometric performances of the HCMM (Heat Capacity Mapping Mission) data,-i.e., a nadir resolution of $0.5 \mathrm{~km}$ and NEDT $=0.3 \mathrm{~K}$ (see Table 1 ) -allowed us to extend the study down to scales of $3 \mathrm{~km}$. The visible channel was used to select cloudfree study areas in the northeastern Atlantic Ocean and the Mediterranean Sea. Only areas in which no large-scale specific features were viewed on fully enhanced images were considered homogeneous and used in this study.

Locations are shown in Fig. 2 and dates are given in Table 2. At each location, the one-dimensional structure functions were computed in four directions, $\theta=0$ (across the satellite track, i.e., approximately east to west), $\pi / 4, \pi / 2$ (along the satellite track) and $3 \pi / 4$.

Examples of the computed structure functions are given in Fig. 3 for VHRR/NOAA-5 and in Fig. 4 for HCMM. The results generally show that the SST field is not exactly isotropic. Nevertheless, the structure functions, if not equal, are roughly parallel on a $\log -\log$ plot, so that the anisotropy is confined in the amplitude $A(\theta)$, i.e.,

$$
D_{T T}(\theta, h)=A(\theta) h^{p}
$$

but the slope $p$ remains very nearly isotropic.

Values of $p$ from 0.5 to 1.3 have been observed in this study with an estimated accuracy of $\sim 0.1$. Using VHRR/NOAA- 5 data, 44 estimations of $p$ were made in the range of scales $40-100 \mathrm{~km}$, and HCMM data were used to make 37 estimations in the range of scales $3-30 \mathrm{~km}$. The corresponding histograms of the observed $p$ are given in Figs. $5 \mathrm{a}$ and $5 \mathrm{~b}$. The most frequent values are $0.9-1.0$ and the mean values are $0.8(3-30 \mathrm{~km})$ and $0.9(40-100 \mathrm{~km})$ with a standard deviation of $\sim 0.2$. About $90 \%$ of the observed values are distributed between 0.5 and 1.1 . The results correspond to a mean value of the powerlaw exponent of the spectrum $n$ of 1.8 in the wavenumber range $0.01-0.3 \mathrm{~km}^{-1}$. 


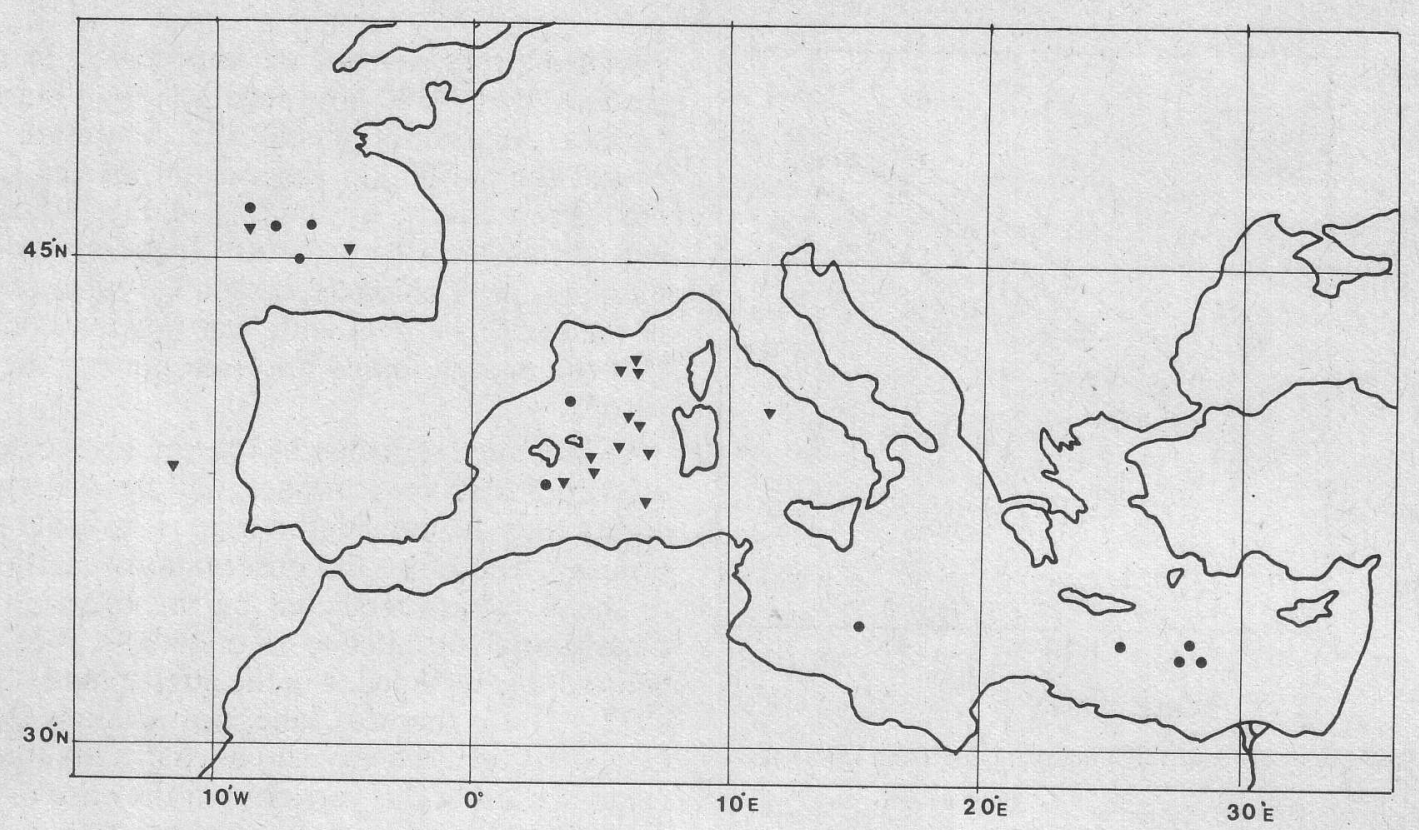

FIG. 2. Geographical locations of the different study areas for HCMM data (triangles) and VHRR data (circles).

The amplitude of the structure functions varied from $10^{-2}$ to $10^{-1}\left({ }^{\circ} \mathrm{C}\right)^{2}$ at $h=40 \mathrm{~km}$. Even after spatial smoothing, it was noted that the noise level tended to slightly reduce the estimated values of $p$ because the structure function of the noise is a constant $(p=0)$. This is particularly true when the noise level $\left(5 \times 10^{-3}\left({ }^{\circ} \mathrm{C}\right)^{2}\right.$ for the HCMM data, 3 $\times 10^{-2}\left({ }^{\circ} \mathrm{C}\right)^{2}$ for the VHRR/NOAA-5 after smoothings) is of the same order as the structure function (see Fig. 1). Whenever possible, the estimates of $p$ were corrected for this effect, but the effect could partly explain the lowest values of $p$.

On the other hand, a mean horizontal thermal gradient would give $D(h) \sim h^{2}$. The areas studied were carefully selected to avoid the existence of thermal gradients which would increase the estimate of $p$ toward larger values; nevertheless some influence on the data could remain. Both of these effects, noise level and horizontal thermal gradients, could partly but not totally explain the spread of the results around the mean value, between 0.5 and 1.3 , which remains significant. There is no evidence of correlation between the estimates of $p$ and the corresponding geographical locations or seasons but, nevertheless, we would guess that it is probably necessary to involve physical processes in the explanation of the observed $p$ values.

\section{Discussion}

Using (6) and the results from this structure function analysis, we obtain a spectral density power exponent with a range of $1.5<n<2.3$. This agrees fairly well with the previous results reported by several authors either from shipborne measurements
(Fieux et al., 1978), or from airborne measurements (Saunders, 1972a), for the one-dimensional temperature spectra (see Table 3). Holladay and O'Brien (1975) attempted to reconstruct the two-dimensional SST field from the tracks of the aircraft survey and found $n \simeq 3$ for the isotropic part of the two-dimen-

TABLE 2. Summary of the different areas studied.

\begin{tabular}{|c|c|c|c|}
\hline Area & Date & Location & $\begin{array}{l}\text { Experi- } \\
\text { ment }\end{array}$ \\
\hline $\begin{array}{l}\text { Eastern } \\
\text { Mediterranean } \\
\text { Sea }\end{array}$ & $\begin{array}{l}\text { 19 Mar } 1978 \\
\text { 05 May } 1978 \\
\text { 08 May } 1978 \\
\text { 14 May } 1978 \\
\text { 17 May } 1978\end{array}$ & $\begin{array}{l}33^{\circ} 00^{\prime} \mathrm{N}, 28^{\circ} 00^{\prime} \mathrm{E} \\
34^{\circ} 00^{\prime} \mathrm{N}, 15^{\circ} 00^{\prime} \mathrm{E} \\
33^{\circ} 00^{\prime} \mathrm{N}, 29^{\circ} 00^{\prime} \mathrm{E} \\
33^{\circ} 30^{\prime} \mathrm{N}, 28^{\circ} 30^{\prime} \mathrm{E} \\
33^{\circ} 30^{\prime} \mathrm{N}, 26^{\circ} 00^{\prime} \mathrm{E}\end{array}$ & $\begin{array}{l}\text { VHRR } \\
\text { VHRR } \\
\text { VHRR } \\
\text { VHRR } \\
\text { VHRR }\end{array}$ \\
\hline $\begin{array}{l}\text { Western } \\
\text { Mediterranean } \\
\text { Sea }\end{array}$ & $\begin{array}{l}\text { 29 Sep } 1977 \\
\text { 29 May } 1978 \\
\text { 29 May-1978 } \\
\text { 11 Jul } 1978 \\
\text { 11 Jul } 1978 \\
\text { 26 Jul } 1978 \\
\text { 28 Jul } 1978 \\
\text { 28 Jul } 1978 \\
\text { 28 Jul } 1978 \\
\text { 14 Aug } 1978 \\
\text { 14 Sep } 1978 \\
\text { 14 Sep } 1978 \\
\text { 14 Sep 1978 }\end{array}$ & $\begin{array}{l}41^{\circ} 00^{\prime} \mathrm{N}, 04^{\circ} 00^{\prime} \mathrm{E} \\
39^{\circ} 05^{\prime} \mathrm{N}, 07^{\circ} 15^{\prime} \mathrm{E} \\
40^{\circ} 05^{\prime} \mathrm{N}, 06^{\circ} 55^{\prime} \mathrm{E} \\
38^{\circ} 55^{\prime} \mathrm{N}, 04^{\circ} 50^{\prime} \mathrm{E} \\
41^{\circ} 55^{\prime} \mathrm{N}, 06^{\circ} 55^{\prime} \mathrm{E} \\
39^{\circ} 20^{\prime} \mathrm{N}, 06^{\circ} 15^{\prime} \mathrm{E} \\
38^{\circ} 15^{\prime} \mathrm{N}, 03^{\circ} 45^{\prime} \mathrm{E} \\
38^{\circ} 35^{\prime} \mathrm{N}, 05^{\circ} 05^{\prime} \mathrm{E} \\
37^{\circ} 40^{\prime} \mathrm{N}, 07^{\circ} 25^{\prime} \mathrm{E} \\
38^{\circ} 30^{\prime} \mathrm{N}, 03^{\circ} 00^{\prime} \mathrm{E} \\
40^{\circ} 25^{\prime} \mathrm{N}, 06^{\circ} 30^{\prime} \mathrm{E} \\
40^{\circ} 35^{\prime} \mathrm{N}, 11^{\circ} 55^{\prime} \mathrm{E} \\
41^{\circ} 40^{\prime} \mathrm{N}, 06^{\circ} 45^{\prime} \mathrm{E}\end{array}$ & $\begin{array}{l}\text { VHRR } \\
\text { HCMM } \\
\text { HCMM } \\
\text { HCMM } \\
\text { HCMM } \\
\text { HCMM } \\
\text { HCMM } \\
\text { HCMM } \\
\text { HCMM } \\
\text { VHRR } \\
\text { HCMM } \\
\text { HCMM } \\
\text { HCMM }\end{array}$ \\
\hline $\begin{array}{l}\text { Northeastern } \\
\text { Atlantic Ocean }\end{array}$ & $\begin{array}{l}\text { 11 Sep } 1977 \\
\text { 14 Sep } 1977 \\
\text { 06 Jan } 1978 \\
\text { 10 May } 1978 \\
\text { 11 May } 1978 \\
\text { 11 May } 1978 \\
\text { 18 Jun } 1978\end{array}$ & $\begin{array}{l}46^{\circ} 00^{\prime} \mathrm{N}, 06^{\circ} 30^{\prime} \mathrm{W} \\
45^{\circ} 00^{\prime} \mathrm{N}, 07^{\circ} 00^{\prime} \mathrm{W} \\
46^{\circ} 30^{\prime} \mathrm{N}, 09^{\circ} 00^{\prime} \mathrm{W} \\
46^{\circ} 00^{\prime} \mathrm{N}, 08^{\circ} 00^{\prime} \mathrm{W} \\
45^{\circ} 15^{\prime} \mathrm{N}, 04^{\circ} 40^{\prime} \mathrm{W} \\
38^{\circ} 35^{\prime} \mathrm{N}, 11^{\circ} 45^{\prime} \mathrm{W} \\
46^{\circ} 00^{\prime} \mathrm{N}, 08^{\circ} 35^{\prime} \mathrm{W}\end{array}$ & $\begin{array}{l}\text { VHRR } \\
\text { VHRR } \\
\text { VHRR } \\
\text { VHRR } \\
\text { HCMM } \\
\text { HCMM } \\
\text { HCMM }\end{array}$ \\
\hline
\end{tabular}




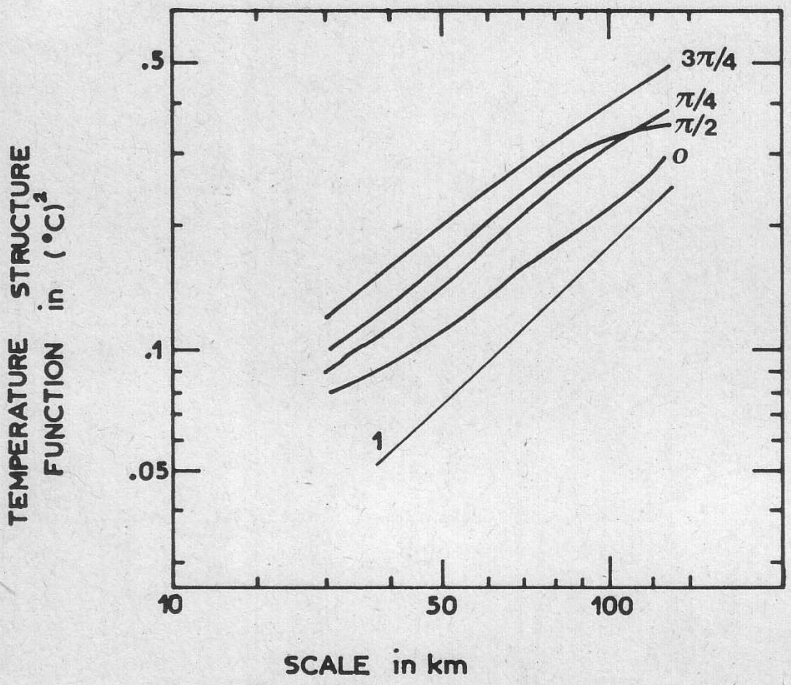

FIG. 3. Example of structure functions computed from VHRR data.

sional spectrum, which probably is an overestimation of the value due to the smoothing of high wavenumbers produced by the SST mapping procedure.

The experimental values, $1.5<n<2.3$, must be compared with those given by turbulence theories. All of the theories assume the existence of an inertial range, i.e., that the considered scales are far from the energy sink and source scales. It is not evident that the range of scales $3-100 \mathrm{~km}$ in the ocean is an inertial one. The scales of input and sink of energy remain puzzling [see a review in Rhines (1977) or Woods (1977)]. The final energy dissipation occurs at molecular scales but larger scales play a role via internal and surface wave breaking. These waves may also generate motion at larget scales via non linear processes (Hasselman, 1971). The interactions between internal waves and mesoscale eddies are uncertain. Müller (1974) predicts that internal waves gain energy from eddies, while the critical-layer absorption theory of Ruddick (1980) suggests the opposite. The typical scales of internal waves are to the lower limit of the studied range and interactions may occur.

Input of kinetic energy related to wind is found at scales of the same order as the wind waves $(100 \mathrm{~m})$, and the meteorological systems ( $1000 \mathrm{~km}$ or more). Energy inflow due to thermodynamic forcing is found at even large scales. All of these scales are one or two orders of magnitude smaller or greater than those studied. At some locations, interior processes such as baroclinic instability may also play an important role in converting energy through nonlinear mechanisms. The scales of these phenomena are on the order of one to six times the internal radius of deformation, depending on the physics of the problem. This radius is of approximately $50 \mathrm{~km}$ in the open ocean and $7 \mathrm{~km}$ in the Mediterranean sea. If these physical processes are of importance in the area studied, the 3-100 km range is not an inertial one. In fact, we cannot specifically determine whether or not the $3-100 \mathrm{~km}$ range is an inertial one from our observations: by looking at Fig. 3 and 4, one can notice that the structure functions do not exhibit any peak characterizing a very energetic scale in the range we deal with, but this may only mean that the energy inputs are from outside the studied range.

In the range of scales $3-100 \mathrm{~km}$, horizontal scales are larger than vertical ones, and the observed variability may be considered a quasi two-dimensional process. Therefore the observations can be related to the $n$ values predicted by the theories of twodimensional turbulence (Kraichnan, 1971) and of geostrophic turbulence in the atmosphere (Charney, 1971). These theories take into account either the conservation of energy and of enstrophy (half of the mean square of the vorticity) in the case of Kraichnan's theory, or the conservation of energy and of the pseudo-potential enstrophy (Charney). Both of these theories agree when predicting the power law of the kinetic energy spectrum: $E_{K}(k) \sim k^{-3}$. But the relations between current and temperature are not obvious and the different mechanisms involved lead to drastically different theoretical power laws for the temperature variance spectrum. Kraichnan's theory, considering that temperature is a passive contaminant implies that $E_{T}(k)$ only depends on $k$ and on the dissipation rates of enstrophy and temperature variance. Then, from a dimensional analysis, $E_{T}(k)$ must follow a $k^{-1}$ power law. Charney made use of the perfect gas law and of the hydrostatic relation to compute a relation between the temperature and the streamfunction and he found the same law for $E_{T}(k)$ as for $E_{K}(k)$, i.e., $E_{T}(k) \sim E_{K}(k)$

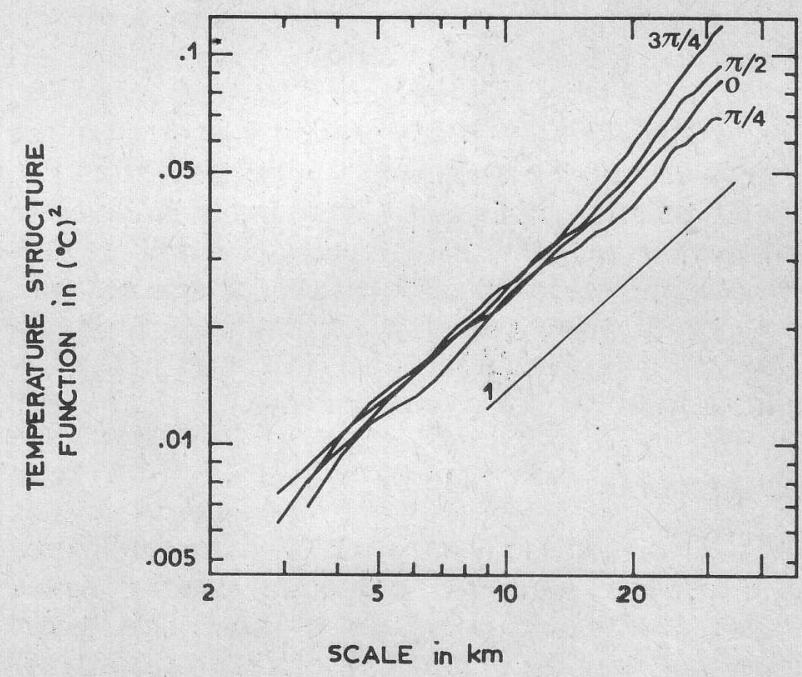

FIG. 4. Example of structure functions computed from HCMM data. 
$\sim k^{-3}$. Also, assuming $E_{K}(k) \sim k^{-3}$, Saunders (1972b) deduced a temperature variance spectrum $E_{T}(k)$ $\sim k^{-5}$, by the use of the thermal wind equation. These examples demonstrate how results may be very different according to various authors. In this study, the mean observed value of 1.8 for $n$ is far from the assessment ( $n=5)$ made by Saunders but falls between the Kraichnan and Charney predictions ( $n=1$ and 3 ). This discrepancy may be due to the fact that the conditions of the theories have not been fully met and namely that the study range is not an inertial one.

Three-dimensional theories of turbulence (Kolmogorov, 1941; Bolgiano, 1962) or space-time variability theories of internal waves (Garrett and Munk, $1972,1975)$ report values of $n$ close to those found in our study $(1.7,1.4$ and 2 , respectively), but the physical basis of their hypothesis can hardly be extended to the mesoscale range.

We may also notice that several experimental studies of air temperature variability mention values of $n$ in agreement with our study at similar range of scales $(100-1000 \mathrm{~km})$. See reviews by Gage (1979) and Panchev (1971). Some of these results are obtained by using spectral analysis on time-series data and equivalent wavenumbers are computed by using Taylor's relation. As the validity of this relation is dubious for such scales, these time-series results must be viewed skeptically. But as for the oceanographic observations, there is no atmospheric theory to explain the observed results.

In summary, the power law exponent $n$ of the spectral temperature variance observed in the range of scales $3-100 \mathrm{~km}$ is nearly 2 . This is very discordant with the values predicted by turbulence theories which are widely spread around this value. Results and conclusions from the present study are very similar to the experimental results published by Saunders (1972a) nearly a decade ago but it is emphasized that further advanced theories are still needed in order to explain the experimental determination of the mesoscale SST variability.
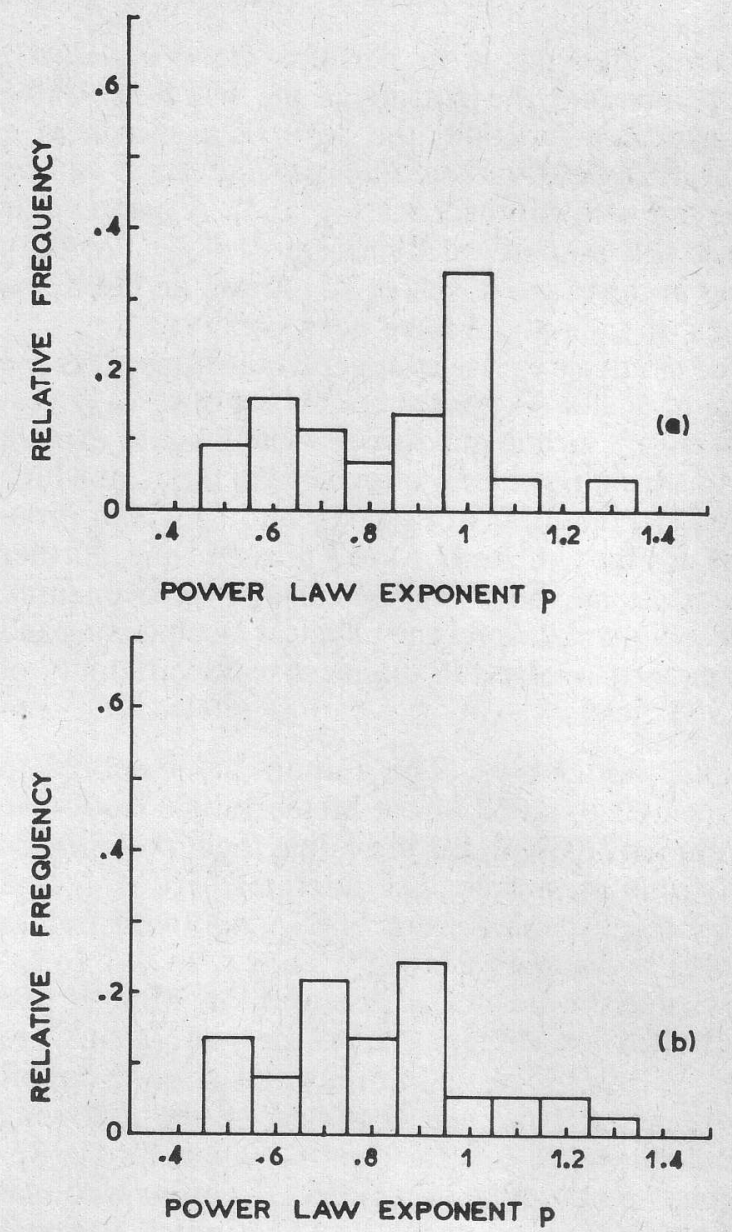

FIG. 5. Histograms of the observed values of the power-law exponent $p$ of the structure function in the range of scales (a) $40-100 \mathrm{~km}$ and (b) $3-30 \mathrm{~km}$.

\section{Conclusion}

This study has proven that it is feasible to estimate the random properties of the SST field in the mesoscale range $3-100 \mathrm{~km}$ from satellite infrared data. As compared with previous analysis of shipborne and airborne observations, the use of satel-

TABLE 3. Summary of observed mesoscale SST variability.

\begin{tabular}{lccc}
\hline \multicolumn{1}{c}{ Authors } & $\begin{array}{c}\text { Range of } \\
\text { scales }(\mathrm{km})\end{array}$ & Power-law exponent $n$ & Comments \\
\hline $\begin{array}{l}\text { Saunders (1972) } \\
\text { Holladay and O'Brien (1975) }\end{array}$ & $3-100$ & $2.2 \pm 0.1$ & $\begin{array}{c}\text { one-dimensional, surface temperature, } \\
\text { airborne infrared sensor } \\
\text { two-dimensional, SST maps from } \\
\text { aircraft surveys }\end{array}$ \\
$\begin{array}{l}\text { Fieux et al. (1978) } \\
\text { This study }\end{array}$ & $1-64$ & 3 & $\begin{array}{c}\text { one-dimensional, surface temperature, } \\
\text { ship-towed sensors } \\
\text { two-dimensional, surface temperature, } \\
\text { satellite data }\end{array}$ \\
\hline
\end{tabular}


lite data allowed us to perform more systematic study, including the isotropy of the SST field. Using the structure function, the power-law exponent $n$ of the SST field variance density spectrum can be retrieved with good accuracy $( \pm 0.1)$. A mean value of 1.8 and a standard deviation of 0.2 have been found in the range of scales $3-100 \mathrm{~km}$, and extreme values of 1.5 and 2.3 have been observed.

The results give rise to several questions: 1 ) Is the range of scales 3-100 km an inertial one? 2) If yes, is there any turbulence theory which would explain the spectrum power law observed? 3) If not, at which scales are the inputs of energy and to which processes are they related? At the present time, further investigations, both theoretical and experimental, are needed to interpret the physical mechanisms and parameters involved in the mesoscale variability of the SST field.

Acknowledgments. The authors are indebted to the receiving station of the Meteorologie Nationale at Lannion, France, for providing them the infrared data from meteorological satellites. HCMM data have been received from NASA as a support to HCMM Investigation No. 15. They wish also to acknowledge the helpful advice of J. M. Monget and the fruitful suggestions of Dr. Crepon. Thanks to L. F. Martin for his aid in the translation. Support for this work has been provided by the following French agencies: CNRS (Centre National de la Recherche Scientifique), CNES (Centre National d'Etudes Spatiales) and CNEXO (Centre National pour l'Exploitation des Océans).

\section{REFERENCES}

Bolgiano, R., 1962: Structure of turbulence in stratified media. J. Geophys. Res., 67, 3015-3023.

Charney, J. G., 1971: Geostrophic turbulence. J. Atmos. Sci., 28, 1087-1095.

Fieux, M., S. Garzoli and J. Gonella, 1978: Contribution à la connaissance de la structure spatiale des courants super- ficiels au large du golfe du Lion. $J$. Rech. Oceanogr., 3 , $4,13-26$

Gage, K. S., 1979: Evidence for a $k^{-5 / 3}$ law inertial range in mesoscale two-dimensional turbulence. J. Atmos. Sci., 36, 1950-1954.

Garrett, C., and W. Munk, 1972: Space time scales of internal waves. Geophys. Fluid Dyn., 3, 225-264.

$\longrightarrow$, and $\_$, 1975: Space time of internal waves: A progress report. J. Geophys. Res., 80, 291-297.

Hasselman, K., 1971: On the mass and momentum transfer between short gravity waves and larger scales motions. J. Fluid Mech., 50, 189-205.

Holladay, C. G., and J. J. O'Brien, 1975: Mesoscale variability of sea surface temperature.J. Phys. Oceanogr., 5, 761-772.

Kneizys, F. X., E. P. Shettle, W. O. Gallery, J. H. Chetwynd, Jr., W. L. Abreu, J. E. A. Selby, R. W. Fenn and R. A. McClatchey, 1980: Atmospheric transmittance radiance: Computer Code LOWTRAN 5. Environ. Res. Pap. No. 697, Air Force Geophysics Laboratory, $233 \mathrm{pp}$.

Kolmogorov, A. N., 1941: The local structure of turbulence in incompressible viscous fluid for very large Reynolds numbers. Dokl. Akad. Nauk. SSSR, 30, 301-305.

Kraichnan, R. H., 1971: Inertial-range transfer in two and threedimensional turbulence. J. Fluid Mech., 47, 3, 525-535.

McLeish, W., 1970: Spatial spectra of ocean surface temperature. J. Geophys. Res., 75, 6872-6877.

Matheron, G., 1970: La Théorie des Variables Régionalisées et ses Applications. Cahiers due Centre de Morphologie Mathématique de Fontainebleau, École des Mines de Paris, $212 \mathrm{pp}$.

Müller, P., 1974: On the interaction between short internal waves and larger scale motion in the ocean. Hamb. Geophys. Einzelachr., No. 23.

Panchev, S., 1971: Random Functions and Turbulence. Pergamon Press, $444 \mathrm{pp}$.

Rhines, P. B., 1977: The dynamics of unsteady currents. The Sea, Vol. 6, Wiley Interscience, 189-318.

Ruddick, B., 1980: Critical layers and the Garrett-Munk spectrum. J. Mar. Res., 38, 135-145.

Saunders, P. M., 1972a: Space and time variability of temperature in the upper ocean. Deep-Sea Res., 19, 467-480.

__ 1972b: Comments on "Wavenumber-frequency spectra of temperature in the free atmosphere." J. Atmos. Sci., 29, 197-199.

Voorhis, A. D., and H. T. Perkins, 1966: The spatial spectrum of short-wave fluctuations in the near surface thermocline. Deep-Sea Res., 13, 641-654.

Woods, J. D.,-1977: Parametrization of unresolved motions. Modelling and Prediction of the Upper Layers of the Ocean, E. B. Kraus, Ed., Pergamon Press, 118-140. 